\title{
Multiple links towards integrating teams for understanding of disease and environment (MULTITUDE)
}

\author{
Alex G. Stewart • Michael H. Ramsey
}

Received: 12 September 2008/ Accepted: 12 September 2008/Published online: 20 November 2008

(C) Springer Science+Business Media B.V. 2008

Geochemists have made important contributions in understanding the cause of environmentally related diseases such as the iodine-deficiency disorders (Fuge and Johnson 1986), fluorine toxicity (Ozsvath 2008), and natural arsenic poisoning (Smedley and Kinniburgh 2005). Similarly, the Society for Environmental Geochemistry and Health (SEGH) has developed a model to describe the relationship between lead in dust and soil and lead in blood (Wixson and Davies 1994), which has played an important part in the development of soil-guideline values in the UK and elsewhere.

Nevertheless, with the continuing and rapid increase in the volume of knowledge relevant to this field, academic disciplines and areas of interests have necessarily become increasingly specialized. The resulting compartmentation has led, too often, to some disciplines inhabiting different 'universes' from others with whom meaningful dialogue and collaboration would be of mutual benefit, even in the environmental health field (Stewart and Pharoah 1996). Concepts,

A. G. Stewart $(\square)$

Cheshire and Merseyside Health Protection Unit, Microbiology Laboratory, Countess of Chester Health Park, London Road, Chester CH2 1UL, UK e-mail: alex.stewart@hpa.org.uk

M. H. Ramsey

School of Life Sciences, University of Sussex,

Falmer BN7 1EL, UK

e-mail: m.h.ramsey@sussex.ac.uk mechanisms, processes, and analytical approaches often cross disciplinary boundaries. The integration of disparate disciplines to examine subject matter from several distinct angles can be frustrating, with different vocabulary and assumptions. However, this integration is an ongoing necessity in order to develop a deeper understanding of the relevant science and to identify fresh multidisciplinary approaches to these complex issues.

This special issue, which contributes towards this integration, contains six papers derived from a workshop held in June 2007 in Liverpool, UK. The general theme was the environment and human health, with a particular focus on building research capacity by forging Multiple Links Towards Integrating Teams for Understanding of Disease and Environment (MULTITUDE). The papers should be read as a whole, since the discussions within the targeted workshops crossed not only disciplinary boundaries but also fertilized each other.

As a result, it became clear to both the participants and the authors that in environmental geochemistry and health, the understanding of uncertainty, both from sampling and measurement (Ramsey 2008) and conceptual (Briggs et al. 2008), is essential for the development of realistic toxicological and exposure data (Hursthouse and Kowalczyk 2008; Ramsey 2008). This in turn will enable the development of successful strategies for the reduction in the effects of contaminants on human health (Farmer and Jarvis 2008). 
The transport and dynamics of single and multiple pollutants (Stewart and Carter 2008) influence not only exposure (Hursthouse and Kowalczyk 2008) but also remediation (Farmer and Jarvis 2008), as do human and social factors in the general public (Briggs et al. 2008; Huby and Adams 2008) as well as in the scientific and professional communities (Farmer and Jarvis 2008; Stewart and Carter 2008).

Also included are seven papers from the directly preceding 25th European Conference of SEGH, also on the same theme. SEGH has a well-established reputation for being at the forefront of interdisciplinary research in this area of growing academic and public interest. These papers indicate the wide breadth of research being undertaken both within the society and in collaboration with researchers and practitioners from many other organizations.

The aim of the workshop and the conference was therefore to bring together expertise from all the different disciplines that conduct research in this area, including not only environmental geochemists and medical scientists, but, in addition, environmental sociologists who understand the social factors that are also associated with disease incidence. The authors of most of the papers from the workshop considered their selected theme from very different perspectives, aiming to produce an integrated approach. They were asked to provide authoritative and broadly accessible reviews of the key issues in five important research themes, from both perspectives. They also drew on the findings of lengthy discussions within one of five targeted workshops, with participants who came from an even wider range of disciplinary backgrounds. The participants were asked to discuss how ideas from their different specializations could be combined to identify and address gaps in current understanding. One other objective of MULTITUDE, which can be further enhanced by the papers in this volume, is to initiate interdisciplinary collaborations that will result in fresh research strategies to address these important topic areas, ready for preparation of new research proposals.

It was only when all of this previously disparate expertise was brought together that the authors could more fully characterize and synthesize the causal connections between environment and health, and suggest more-effective ways of improving human health by using this integrated approach.
The original topics of the five targeted workshops, and the authors of the corresponding papers in this volume, are:

1. Transport and dynamics of toxic pollutants in the natural environment and their effect on human health (Hursthouse and Kowalczyk).

2. Uncertainty in risk assessment and epidemiology (Ramsey; Briggs, Sabel and Lee).

3. Social, economic, and behavioral factors in the genesis and health impact of environmental hazards (Huby and Adams).

4. Strategies for improving health in contaminated situations (Farmer and Jarvis).

5. The effects of multiple toxic pollutants on health (Stewart and Carter).

Acknowledgments The workshop was conceived and developed by the European Committee of SEGH and was administered via a NERC grant (NE/E009484/1) and supported financially by the Joint Environment and Human Health Programme, funded by (1) Natural Environment Research Council (NERC), (2) Department for Environment, Food \& Rural Affairs (Defra), (3) Environment Agency (EA), (4) Ministry of Defence (MOD), (5) Economic \& Social Research Council (ESRC), (6) Medical Research Council (MRC), (7) The Wellcome Trust, (8) Biotechnology \& Biological Sciences Research Council (BBSRC), (9) Engineering \& Physical Sciences Research Council (EPSRC), (10) Health Protection Agency (HPA). We are grateful to the Health Protection Agency (North West Region) for hosting both the workshop and the conference. We also acknowledge the invaluable input to the workshop discussion from the participants who included Rupert Adams, Louise Ander, Katy Boon, David Briggs, Andrew Broadway, Sarah Bull, Joy Carter, Mark Cave, Iroegbu Chinny, Paul Cleary, Stewart Craig, John Farmer, Gillian Gibson, Eliza Giubilato, James Grellier, Meg Huby, Andrew Hursthouse, Richard Jarvis, Ben Klinck, Samira Kofali, Gibby Koshy, George Kowalczyk, Maria Lathouri, Jennifer le Blond, Hong Li, Paolo Luria, Ian Martin, Iain McClelland, Gordon Mcpherson, Theresa Mercer, Paul Nathanail, Jenny O'Reilly, George Onuoha, Ann Power, Paul Quimby, Mike Ramsey, Lesley Rushton, Sohel Saikat, George Shaw, Thomas Shepherd, Alex Stewart, Paul Syms, Mamoona Tahir, Kevin Taylor, Jacqueline Yvette, Thomas Penelope Toff, Graham Urquhart and Chaosheng Zhang.

\section{References}

Briggs, D., Sabel, C. E., \& Lee, K. (2008). Uncertainty in epidemiology and health risk and impact assessment. Environmental Geochemistry and Health. doi:10.1007/ s10653-008-9214-5.

Farmer, J. G, \& Jarvis, R. (2008). Strategies for improving human health in contaminated situations: A review of 
past, present and possible future approaches. Environmental Geochemistry and Health. doi:10.1007/s10653008-9209-2.

Fuge, R., \& Johnson, C. C. (1986). The geochemistry of iodine-a review. Environmental Geochemistry and Health, 8, 31-54.

Huby, H., \& Adams, R. (2008). Interdisciplinarity and participatory approaches to environmental health. Reflections from a workshop on social, economic and behavioural factors in the genesis and health impact of environmental hazards. Environmental Geochemistry and Health. doi: 10.1007/s10653-008-9212-7.

Hursthouse, A., \& Kowalczyk, G. (2008). Transport and dynamics of toxic pollutants in the natural environment and their effect on human health: research gaps and challenge. Environmental Geochemistry and Health. doi: 10.1007/s10653-008-9213-6.

Ozsvath, D. L. (2008). Fluoride and environmental health: A review. Reviews in Environmental Science and Biotechnology. doi:10.1007/s11157-008-9136-9. Accessed 12 Sept 2008.
Ramsey, M. H. (2008). Uncertainty in the assessment of hazard, exposure and risk. Environmental Geochemistry and Health. doi:10.1007/s10653-008-9211-8.

Smedley, P., \& Kinniburgh, D. G. (2005). Arsenic in groundwater and the environment. In O. Selinus, B. J. Alloway, J. A. Centeno, R. B. Finkelman, R. Fuge, U. Lindh, et al. (Eds.), Essentials of medical geology: impacts of the natural environment on public health (pp. 263-295). Amsterdam: Elsevier Academic Press.

Stewart, A. G., \& Carter, J. (2008). Towards the development of a multidisciplinary understanding of the effects of toxic chemical mixtures on health. Environmental Geochemistry and Health. doi:10.1007/s10653-008-9210-9.

Stewart, A. G., \& Pharoah, P. O. D. (1996). Clinical and epidemiological correlates of iodine deficiency disorders. In J. D. Appleton, R. Fuge \& G. J. H. McCall (Eds.), Environmental geochemistry and health (pp. 223-230). London: Geological Society.

Wixson, B. G., \& Davies, B. E. (1994). Guidelines for lead in soil. Environmental Science and Technology, 28, 26A-31A. 